2004-1228

\title{
Mentoring Students To Technology Careers
}

\author{
Narayanan M. Komerath, Marilyn J. Smith \\ School of Aerospace Engineering, Georgia Institute of Technology, \\ Atlanta, GA 30332-0150
}

\begin{abstract}
This paper summarizes three years of experience from the Computer Science, Engineering and Mathematics Scholarship (CSEMS) program funded at Georgia Institute of Technology (GIT) by the National Science Foundation (NSF). Features of the program include a partnership between academic faculty and the Financial Aid department, a strong mentoring program involving academic faculty, and guidance of student participation in activities that broaden their horizons. A grade point requirement profile has been developed, to support students as they adjust to the demands of a technical education. Program data and samples of student work are presented. A seminar-reporting system encourages students to discover and explore their own interests. Assessment results indicate success in enhancing retention and supporting diversity. The paper discusses experience with the faculty-mentoring program, metrics and success in seeing students through to successful graduation, and glimpses how the program has made a difference to the ability of many students to reach careers of their interest.

Introduction

When demand for technology graduates outstripped supply in the 1990s, the United States Congress expanded the recruitment of professionals from overseas. Accompanying that temporary program, Congress also assigned a substantial fraction of fees paid to the Immigration and Naturalization Service by employers seeking overseas professionals, to the National Science Foundation ${ }^{1}$. These funds were specifically aimed to increase the supply of technology professionals in the future US workforce. The Computer Science, Engineering, and Mathematics Scholarships (CSEMS) program was set up using these funds. Educational institutions were encouraged to compete for these funds, generally for two- to- four-year awards. This program has several special features - the funds were to be used for scholarships, as distinct from workstudy, research internship or other such arrangements. The intent was clearly to enhance the supply of enthusiastic professionals in the above technology-related disciplines, and hence some level of personal attention to the success of the students was essential.
\end{abstract}


This paper describes how the CSEMS program at the Georgia Institute of Technology (Georgia Tech, GIT) was set up and operated to meet these objectives. The environment and reasoning which drove the strategies and policies are discussed, and the resulting experience indicated.

Georgia Tech's Colleges of Engineering (9 Schools), Sciences (School of Mathematics), and Computing, have an undergraduate full-time enrollment totaling over 7,500. Resources to assist students in funding their education come from a variety of sources, a major source being the State of Georgia HOPE scholarship for Georgia residents. Students of many socio-economic backgrounds all over the US choose Georgia Tech, a public institute of higher learning, partly due to its low cost compared with comparably-ranked institutions.

\section{Program Objectives \& Elements}

The objectives of the scholarship program are to enable access to a top-quality education to the most deserving students and to ensure the best guidance for their success. It was anticipated that many such students would be from under-served backgrounds that include rural and inner-city environments. The basic elements of the program are to:

- introduce the most deserving and talented students to the excitement of CSEM careers,

- provide access to a top-quality education, and

- furnish the best guidance for their success and development.

\section{The Environment of the FAST program}

Table 1 presents benchmark data ${ }^{2,3}$ for our present program as of academic year 2000 - $^{\circ} 01$. Demographics are compared below, and we see that the program is successful in attracting a more diverse demographic pool than the overall student population at GIT. We note that diversity is not used as a criterion in selecting students for this scholarship. Should two students have identical credentials and need but differ only in non-merit aspects, we certainly hope that we will be able to find support for both. The more diverse demographics perhaps reflect need and interest distributions. The lower percentage of women students in CSEMS should be viewed with the fact that the university statistics are for the overall institute, not the subset of the more male-dominated CSEMS colleges.

Table 1. FAST demographics compared to overall GIT US citizen/resident undergrads.

\begin{tabular}{|l|c|c|c|c|c|c|}
\hline & $\begin{array}{c}\text { African- } \\
\text { American }\end{array}$ & $\begin{array}{c}\text { Asian- } \\
\text { American }\end{array}$ & Caucasian & $\begin{array}{c}\text { Hispanic- } \\
\text { American }\end{array}$ & $\begin{array}{c}\text { Native- } \\
\text { American }\end{array}$ & Women \\
\hline FAST (CSEMS) & $17.6 \%$ & $24.7 \%$ & $49.4 \%$ & $7.1 \%$ & $1.2 \%$ & $25.9 \%$ \\
\hline $\begin{array}{l}\text { GIT (all colleges, } \\
\text { AY00-01) }\end{array}$ & $9.3 \%$ & $12.4 \%$ & $75 \%$ & $3 \%$ & $<1 \%$ & $28 \%$ \\
\hline
\end{tabular}

The opportunities available at Georgia Tech are many, given its active research programs and industry partnerships. Students use these opportunities to a considerable extent: over 100 of our faculty include undergraduates on their research teams ${ }^{4}$. Roughly $33 \%$ to $40 \%$ of undergraduates find cooperative education (Co-op) positions with industry and government, providing experience and financial boosts as they go through school, and giving GIT the largest optional 
engineering Co-op program in the United States. One issue of interest to the CSEMS program is to make students aware of these opportunities early and to provide experienced guidance on how and when to pursue given opportunities.

\section{Project Team}

The CSEMS project at GIT is known as "Financial Aid for Success in Technology" (FAST). The CSEMS program specified that very little of the project funds were to go into administrative costs. Realizing this, a simple project management structure was set up, with team effort as the guiding principle. The project team consists of ten faculty from the Colleges of Engineering and Computer Science and two financial aid experts from the Student Success Center. A unique feature of many CSEMS programs around the country, including GIT, is that the project carries no overhead - all CSEMS funds are directly used as scholarships for students. At Georgia Tech, $100 \%$ of the NSF funds go directly to the students - no administrative or other costs are charged, and none of the faculty involved get any release time or such other benefits from this program.

This feature obviously required that the faculty mentors were people who had the experience and interest to be effective in this role, without significant addition to their workload. Thus, mentors were carefully selected based on their known records of success and interest in working with undergraduates in such roles. The Financial Aid experts expressed eagerness to participate in a program that would increase the resources available to the students seeking financial aid, and again, they brought the existing strengths of a powerful database system that was used to administer a variety of other aid resources.

\section{Recruitment Strategy and Experience}

Given the large pool of well-qualified students at GIT, there has been no shortage of qualified applicants for the FAST program. However, recruitment efforts are conducted through various means for identifying and contacting prospective students. The Space Grant Consortium at GIT (whose director is faculty mentor on this project) visits numerous middle schools and high schools throughout Georgia every year, and includes the FAST brochure in their communications. Similarly, Georgia Tech's annual Engineering and Computing Career Conference $(\mathrm{ECC})^{5}$, sponsored by the Women in Engineering program (whose director is also a co-PI of this project), provided an opportunity to recruit many individuals, in particular women students. The FAST opportunity is also part of the package of initial communications from Georgia Tech's Office of Admissions to newly accepted freshman and transfer students. The program is advertised on the Financial Aid website, and a special site ${ }^{6}$. As the program matures, referrals from faculty advisors and the Financial Aid Office identify students in dire need. Recently, we have seen applicants who are transferring from another school with a CSEMS project, and contact comes as a result of the NSF's conference of CSEMS Principal Investigators ${ }^{1}$.

The FAST program at GIT commenced with the first funds arriving in October 2001. Thus the first semester where scholarships were available to students in time to pay fees, was Spring 2002. The application process consisted of 4 steps: 
1. Submitting the FAFSA form to qualify for Federal aid and identify the maximum permitted amount of aid receivable under this program. This is required by CSEMS.

2. Downloading a one-page form from the Financial Aid website, filling it with details such as class standing, GPA, and other aspects required to evaluate qualifications of the overall CSEMS program and the specific Georgia Tech requirements.

3. Writing and attaching a 1-page to 2-page free-form "essay" delineating the candidate's interests in a career in technology, and beginning the process of getting candidates to think about "where" they planned to be in 5, 10 and 20 years' time.

4. Mailing the package to the Financial Aid Office (or to the project director), along with unofficial transcripts for evaluation.

\section{Selection Criteria \& Process}

The Financial Aid office passed FAFSA-qualified applications to the PI. For the first round, each application was seen and evaluated by at least two faculty. As far as possible, one evaluator was from the applicant's field of interest. Given our experience level, there was little need for "normalization" of grading standards, though the need for this was tested. Candidates were rankordered within each evaluator's set, across evaluators, and eventually checked against Financial Aid's intimate knowledge of each student's financial circumstances. For later semesters, the process was simplified. A sub-team including the Financial Aid Office and two faculty members did evaluations. Recommendations from other faculty were also considered carefully.

\section{Distribution Level and Designing for Steady State}

Individual awards were adjusted between $\$ 500$ per semester (in cases of marginal need) and $\$ 1500$ (in cases of dire need). Later awards were set at $\$ 1000$ per semester (with summer possible in addition) with exceptions handled as they arose - by individual contacts between the student, mentor and Financial Aid. The first batch of scholars was selected across the spectrum of class standing from freshman to senior, with due thought given to program viability, enabling us to recruit more students as some graduated and to set up a working rotation with Co-Op students. Thus 37 students were selected in Spring and Summer 2002, followed by 27 in the next year (Fall, Spring and Summer 2003) and 20 more in Fall 2003, with a 3-4 additional awards in Spring 2004. The total number of students involved in the program to-date is thus 87 , of whom the majority has been continuing for more than one semester. In today's "steady-state" operation, this number includes some who have graduated, some whose scholarships were not renewed (for one semester, with the option to reapply) because of failure to achieve minimum performance, and several who are on Co-Op assignments.

Mentoring Experience and Requirements from Participants

A major part of the effort in operating this program, from the faculty team's perspective, is the mentoring - an indication of effective use of faculty and student time. Participants were required to satisfy certain minimal criteria, in addition to maintaining the minimum specified GPA:

- Meet their assigned mentors at least once a semester and discuss their progress, evolving strategic plans, and to identify suitable opportunities for development. 
- Find and attend two seminars given by visiting faculty (research seminars) or industry visitors to obtain a perspective of the industrial environment and problems of interest.

- Submit 1-page to 2-page summaries of what they learned by attending each seminar.

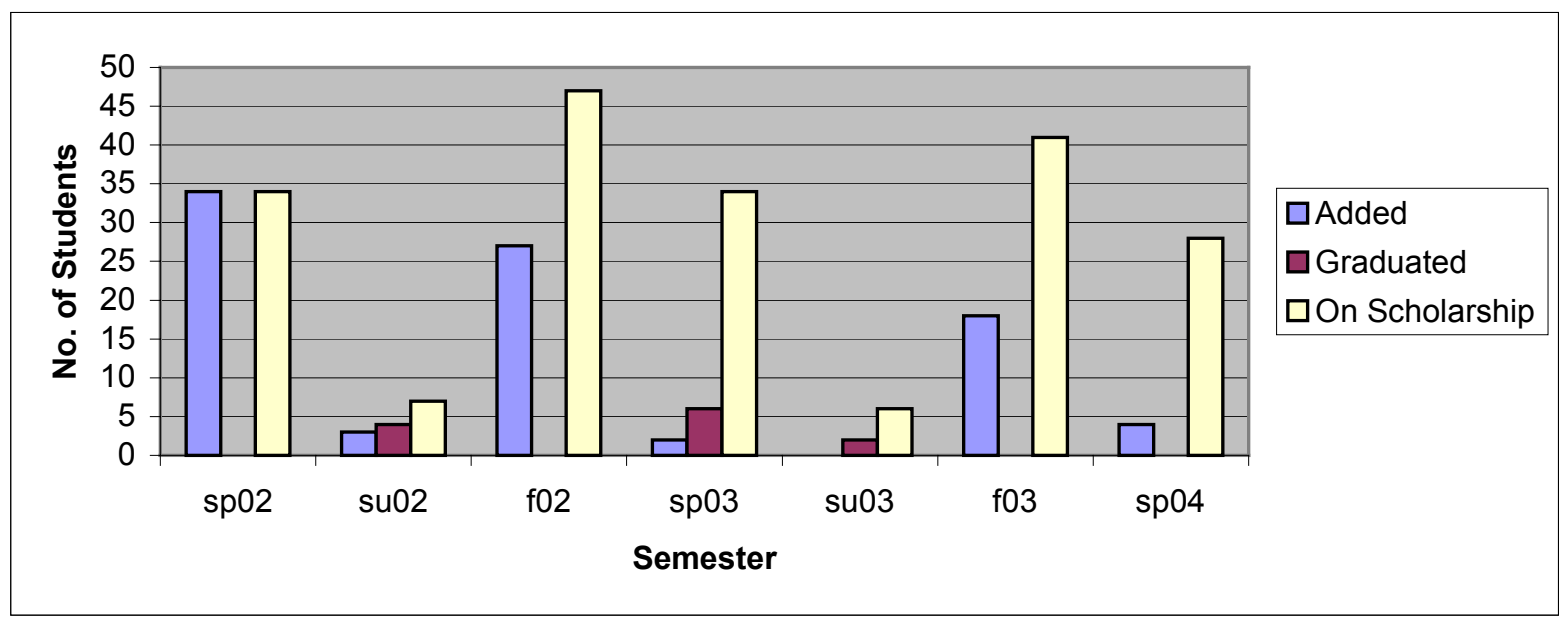

Figure 1: Number of active students by semester

The Seminar Requirement Experience

Undergraduates are less likely than graduate students to attend professional-level seminars on their own - and even in a research university, many students go through their four years with little awareness of the research and industrial development activities that occur in the university. While GIT has a gratifying overall rate of undergrad participation in research projects, it is likely that students who come from technologically aware families in large metropolitan areas are disproportionately represented among such students. Thus the seminar requirement was aimed at undergrads who were least likely to be cognizant of the vast opportunities available to them. At the proposal stage we visualized a special seminar series and with invited experts to talk to our students. This idea was abandoned for three reasons:

- Mandatory attendance at such seminars is a hurdle, given the diverse class schedules.

- Given the diversity of our students, invited speakers to such mandatory seminars would have to be constrained to speak on topics of rather general interest across disciplines.

- It became obvious that there was already such a wealth of seminars scheduled every week at our campus, catering to a wide range of interests. We decided to let students explore and discover their own interests. Table 1 shows a few examples of seminars selected by students.

Table 2: A few examples of seminars chosen by FAST students.

\begin{tabular}{|l|l|l|}
\hline Presenter & Title & School, date \\
\hline Dr. C. De Melo & Nobel Prizes Related to Superconductivity and Superfluidity & Phy 10/2003 \\
\hline Dr. A. White & Lifecycle Simulation & AE 9/2003 \\
\hline $\begin{array}{l}\text { Dr. Ron } \\
\text { Calabrese }\end{array}$ & $\begin{array}{l}\text { Modeling a Neuronal Network at Three Different Levels: } \\
\text { Lessons from the Leech Heartbeat Central Pattern Generator. }\end{array}$ & BME 3/2002 \\
\hline Dr. P. Wadler & "As natural as 1-2-3" & CoC 9/2003 \\
\hline Dr. E. Edwards & "Environmental Applications of DNA Microarrays" & BME 11/2003 \\
\hline
\end{tabular}


Students immersed in full-time CSEMS programs are using the seminar requirement to attend research presentations well outside their coursework, broadening their horizons. In writing a summary of what they learned, students stated their own well-considered opinions on what the presenters stated, and commented on presentation styles. This worked far better than if the seminar selection had been left entirely up to the faculty mentors. As the program progressed, seminar options were broadened to best meet diverse needs:

- Freshmen and sophomores are encouraged to go to the Division of Professional Practice and Student Success Center, who arrange Co-Op and Internship opportunities, and take seminars and one-to-one help with interviewing and resume writing.

- Juniors and seniors are encouraged to attend at least one PhD or Masters Thesis defense to learn what kinds of research and student expectation levels occur in graduate school.

Experience with this requirement confirms that it is essential and successful. Students who took the initiative early to explore for seminars have sent in abstracts that reflect genuine excitement and interest. The discipline of having to plan, explore, find and actually attend two seminars was a tough challenge to several students. Most responded to reminders. Those who did not were put on "probation" in the scholarship program for one semester, and failing that, were asked to reapply in competition with new applicants. In most such cases, this appears to have motivated them to find other avenues of support, involving research internships, Co-op positions, or other jobs. Though these students may not agree with us now, we view them as successes - in motivating them to explore avenues of funding. They remain eligible to reapply.

In some cases students find other sources of support or become otherwise ineligible through the FAFSA criteria. In some cases, FAFSA is simply inadequate to assess the true financial condition and need of the student. An example from some years ago was a student whose family business disappeared suddenly, leaving them without real means of support - but the student was ineligible to receive any Federal support. Solutions are explored between the PIs and Financial Aid. The solution is sometimes to shift the student to non-Federal sources. The existence of the FAST program makes a huge difference by giving the student the benefit of having two or three experienced people trying to tailor the most appropriate financial aid solution.

Progressive GPA scale

A major issue with most scholarship programs is that the first year at a major technological institution is a shock to many students. This is especially true for students from outside the top schools in large metropolitan areas, where the concentrations of technology and business provide

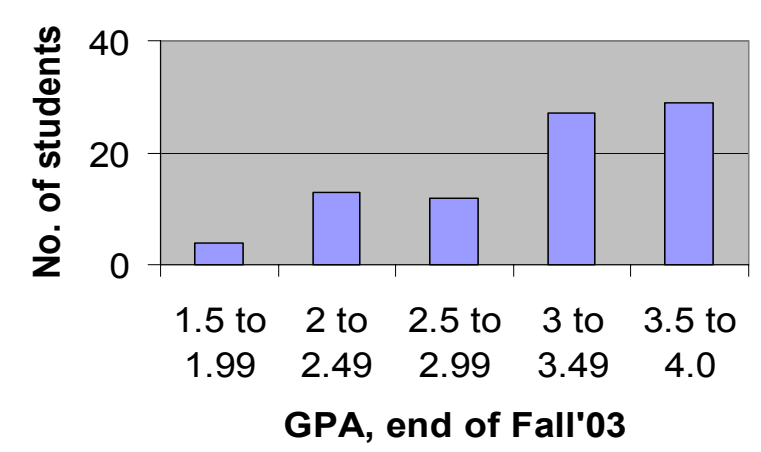
extremely high "comfort levels" with technology. One result is that at the end of the standard 30-semester-hour clock, student GPAs frequently slip below 3.0, and they lose their scholarships. CSEMS offered a unique opportunity for faculty advisors to alleviate financial pressure and mentor these students as they adapted to the collegiate environment.

Figure 2: Current GPA distribution

Proceedings of the 2004 American Society of Engineering Education Annual Conference \& Exposition. Copyright (C)2004 by the American Society of Engineering Education. 
At the outset, we developed a unique "sliding GPA scale" (see Table 3). A 2.0 GPA is required at graduation. We set the Senior GPA target at 2.6. Most students in the program continue to have excellent GPAs, as shown in Figure 2 - but this scale allows us to reach out to those who need some help. In some cases, students were on "probation" for a semester as they worked to improve their GPAs - but retained the crucial support of the scholarship.

Table 3. Summary of FAST Scholarship Requirements

\begin{tabular}{|l|l|l|l|}
\hline & $\begin{array}{l}\text { Cum } \\
\text { GPA }\end{array}$ & $\begin{array}{l}\text { Recommended } \\
\text { Activities Outside Classes }\end{array}$ & $\begin{array}{l}\text { Mentoring } \\
\text { Requirements: Minima }\end{array}$ \\
\hline $\begin{array}{l}\text { Freshman } \\
\text { Hrs.0-30 }\end{array}$ & 2.0 & $\begin{array}{l}\text { Seminar series; One "project team", limit of } \\
\text { 1 extra-curricular }\end{array}$ & Twice a semester \\
\hline $\begin{array}{l}\text { Sophomore } \\
\text { Hrs.30-60 }\end{array}$ & 2.3 & $\begin{array}{l}\text { Seminar series; Two project teams; 2 extra- } \\
\text { curricular; peer-leader of freshmen }\end{array}$ & $\begin{array}{l}\text { Twice a semester. Resume } \\
\text { writing; interviewing. }\end{array}$ \\
\hline $\begin{array}{l}\text { Junior } \\
\text { Hrs. 60-90 }\end{array}$ & 2.4 & $\begin{array}{l}\text { Two project teams including one research/ } \\
\text { design competition; 3 extra-curricular; Peer } \\
\text { leader }\end{array}$ & $\begin{array}{l}\text { Once per semester. } \\
\text { Interviewing skills; grad } \\
\text { school/ career surveys }\end{array}$ \\
\hline $\begin{array}{l}\text { Senior } \\
\text { Hrs 90-136 } \\
\text { extra-curricular. Peer leader }\end{array}$ & $\begin{array}{l}\text { Once per semester. Grad } \\
\text { school applications; letters; } \\
\text { scholarships }\end{array}$ \\
\hline
\end{tabular}

Evolution and Impact

As the program moves through its $3^{\text {rd }}$ year, the steady-state operation is producing the intended results. The first large group is moving through graduation. As Figure 3 shows, students are from all CSEMS areas, though so far only two Mathematics students have applied. Anecdotal

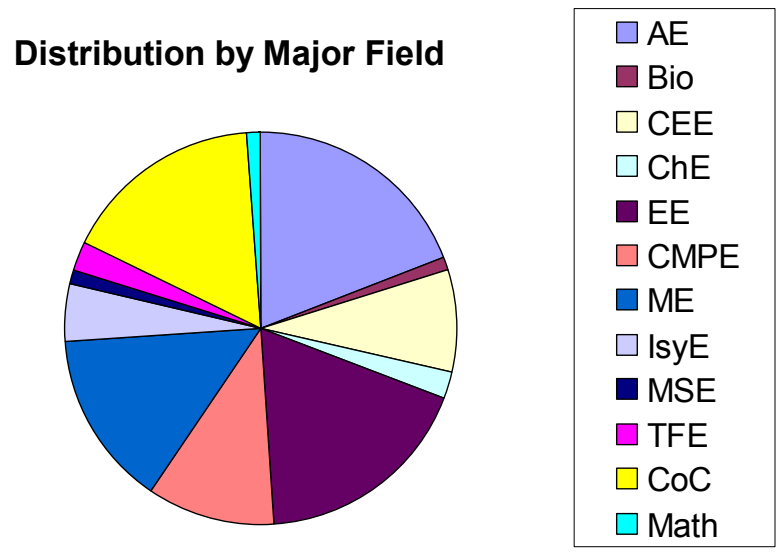

Figure 3: Fast scholars bv maior field. evidence is showing that the FAST program is making a crucial difference in enabling many students to devote fuller attention to studies and graduate earlier. In an example, where a student's parents both lost jobs, this program along with mentoring, has enabled the student to keep moving towards graduation.

An important feature is how each student reacts to the collegiate experience. Many students come to CSEMS programs with personal-interaction skills seriously lagging their exceptional technical aptitudes. Such students appear to be more at risk of failure, merely through not having the ability to recognize what a small change in discipline / attitude could achieve. We are learning to diagnose this, and to direct such students to sources of help, until they gain the necessary perspective and understanding of people around them. It is not known to what extent such problems are prevalent among today's undergraduates - they become more evident when the student is dealing with faculty who are far removed from their day-to-day classes. 
Metrics \& Assessment

Project assessment is proceeding in this third year. Graduates are being polled, and the impact of each feature is being quantified. Note from Fig. 1 that a steady-state number of roughly 80 to 90 is feasible, since several students are on Co-Op assignment each semester and do not qualify for, or need, funding during that semester. Several indicators are extremely encouraging:

\section{Increased retention of students to degree achievement}

One metric is that out of 90 participants to-date, we have lost only 4 to academic problems and none to lack of finances. In 3 (and probably all 4) of these cases, the student was also leaving the Institute. In at least 5 anecdotal cases, mentor intervention with focused assistance from Financial Aid, has made the difference to find the finances to let students complete their degree programs. "Persistence Rate" measured by Graduation Inside 6 Years for the 1997 cohort at GIT, is $69.3 \%{ }^{7,8}$

Of the 90 students, only two (overall) have changed to majors outside the CSEMS disciplines. "Retention rates" advertised by universities count transfers out of engineering/science into other colleges on campus as "retained". Table 4 compares data for FAST with the numbers for just the CSEMS units at GIT ${ }^{8}$, counting transfers out of CSEMS the same as dropout from GIT. Note that FAST's overall retention rate is higher than the freshman rate, because in our first year, many of the students recruited were beyond the freshman year. For GIT, freshman retention data for the latest year are used.

Table 4: CSEMS retention data comparison

\begin{tabular}{|c|c|c|}
\hline & Freshman Ret. & Overall ret. \\
\hline FAST & $94 \%$ & $94.4 \%$ \\
\hline GITCoE,CoC,CoS & $87 \%$ & $84.1 \%$ \\
\hline
\end{tabular}

Students on FAST do have a higher overall GPA than the overall GIT CSEMS cohort: Mean of 3.1 (distribution shown in Fig. 2) vs. 2.7 - however, past studies have generally shown a weaker-than-expected correlation between GPA and retention within individual disciplines. Students with higher GPAs may have higher motivation, but also more initiative and mobility in going where they want to go - and these goals evolve unless they remain strongly interested in their original choice.

\section{Increased numbers of well educated and skilled employees in technical areas}

The FAST program makes an important statement: that staying in technical disciplines is exciting, and promises a productive and satisfying life for people who have the right kind of aptitude and interests. The recruitment essay, and the seminars, all emphasize this. Students, who may otherwise have moved into management at the earliest, now see more opportunities to grow in technical disciplines. Ten students have graduated with our help, and four more are in their graduating semester. There is no indication that any of the graduates had to go outside the CSEMS fields for employment. Data on precise jobs are slow to arrive, and we know of only four confirmed in CSEMS jobs or graduate school. 
3. Strengthened partnerships with high technology industry.

Thirteen students are in the Co-Op program - while seven more who are in the Co-Op program will be funded when they return to campus, and four more hold part-time jobs such as research assistantships. We do help minimize their need for such jobs, but research experiences are springboards to success in studies, motivation and future higher education and employment. CSEMS is used by several students as a helping hand and a springboard, not throughout their GIT careers. The average stay of a student on the FAST scholarship is for 2.3 semesters, the median is 2 semesters, and the corresponding mean and median amounts given to each student overall are \$2256 and \$2000. Sixteen students have received 4 semesters of funding and 4 additional students have received 5 or 6 semesters of support. The lower average and median reflect new students and those who may have need during the final stages of matriculation.

\section{Improved student support programs at institutions of higher education}

The demonstration of faculty-Financial Aid Dept. teamwork has set a precedent for solving problems of students. The flexibility and faculty attention aspects of FAST are illustrated by the fact that students get on and off the scholarship depending on their FAFSA need situations - if need is below the Federally allowed limit for one semester, but goes back up again the next semester, our scholarship does not leave the student out in the cold. This is particularly true of students who are co-oping or whose parents own their own businesses.

\section{Improved educational opportunities for students in the named disciplines}

The FAST program certainly provides crucial financial support to enable students to concentrate on their studies full-time. The contact with faculty mentors opens up many opportunities of which undergraduates are usually not aware - regarding choices of diverse fields of study, and graduate school opportunities. For example, many students are simply not aware that graduate students can get Fellowships or assistantships that allow them to pursue graduate degrees fulltime without imposing on their parents' finances. The number of graduates is as yet too small for meaningful statistics to be generated on the question of "how much difference did FAST make to your ability to get the degree you wanted?" until the effect of Mentoring is realized fully.

\section{Summary of Lessons Learned}

The program is certainly successful in all the key aspects at which we aimed, and especially encouraging is the success of those features that we initially saw as "risky":

1. Finding good Academic Faculty Mentors - for zero "pay" - by simply asking them to volunteer. This has indeed been a rewarding experience, in that each of the Mentor volunteers brings very special insights, guidance methods and experience, with a common denominator of dedication and caring.

2. The sliding GPA scale. Far from the feared pitfall of sending many students into a low trajectory, experience shows that the students more than justify our faith in their ability and determination to work hard. This is especially true when the FAST program has reduced or eliminated their need to work at part-time jobs while studying full-time.

3. Zero-overhead administration. With the simple program management structure that we set up we have enabled every participant to focus on what s (he) wants and is skilled to do. Thus, the only formal "staff meetings" ever conducted on this program are two meetings involving necessary PIs and the Financial Aid office - one to lay out the initial plan, and one to set out 
the recruitment schedule for the second year. Everything else has been done by e-mail, phone, lunch or informal conversations.

4. Finding enough seminars for students to cater to their own interests. Once we realized that we should let the students find such seminars, and saw the remarkable diversity of their choices, this has become a strong component of our efforts to broaden the perspective of the scholars while they are still undergraduates.

5. Locating students who have need. Mentors and student referrals are increasing each semester. The faculty who have administered this program have found it especially rewarding since there is now a synergism with the Financial Aid Office.

The tougher lessons

1. We are concerned that some of the first-time students exhibit what appears to be a "take the money and run" attitude. The reasons for this apparent attitude need deeper examination, and the available repertoire of motivating strategies / responses must be fine-tuned. There was an apparent correlation between school and attitude, and a correlation to the absence of a tradition of faculty mentoring of undergrads in those schools. We tried getting assistance from College administrators and counseling/correction by the Dean of Students' office, but found those to be non-viable. The solution that we found is to seek student input on the right mentors to recruit from those schools and approach them, armed with the student recommendation as the recruitment tool (successful this Spring). Saying: "Your students told us that you are the most caring advisor in your school" is a far better persuasive technique than: "your Dean told us..".

2. Although the application process and the "requirements" seem simple and non-intrusive to us, these still appear to pose large obstacles to many students. Efforts continue to make it easier for them to remember the requirements and to find seminars. The new FAST web site for students is already shown to be a positive step in this direction.

3. It is not easy to get post-graduation data - a problem that we found to be "universal" when we attended the NSF's CSEMS PI meeting.

\section{Acknowledgements}

The authors gratefully acknowledge the support by NSF of the Georgia Tech FAST program under the CSEMS initiative. The generous assistance from Faculty Mentors Dr. Gary May, Mahera Philobos, Erian Armanios, Jeffrey Streator, Colin Potts, William Sayles, and the tireless efforts of Financial Aid department professionals Jerry McTier, Scott Greene and Marie Mons are gratefully acknowledged.

\footnotetext{
Bibliography

${ }^{1}$ National Science Foundation CSEMS PIs Meeting, Arlington, VA Fall 2003

2 Bramblett, S., "College of Engineering Retention Data- Special Request”. Georgia Institute of Technology, Office of Institutional Research and Planning. Nov. 1999

3 Anon, "Graduation Analysis: First-Time Freshmen, Fall 1993". Office of Institutional Research and Planning, Georgia Institute of Technology, December 6, 1999.
} 


\footnotetext{
${ }^{4}$ Moore, G., "OMED: Educational Services In Educational Partnerships: Moving Toward the Next Millennium", Tower Conference, April 5, 2001.

${ }^{5}$ Women in Engineering website at the College of Engineering, Georgia Institute of Technology. http://www.coe.gatech.edu/wie

${ }^{6}$ Website of the FAST project, the NSF-CSEMS project at Georgia Institute of Technology. http://www.ae.gatech.edu/ msmith/FAST/Index.html

7 Anon, “Common Data Set”. Institutional Research and Planning, Georgia Institute of Technology, http://www.irp.gatech.edu/Common_Data Set page.html

${ }^{8}$ Gardner, D., "Engineering/Science/Computing Retention and Graduation Rates". Office of Institutional Research and Planning, response to data request, Jan. 2004.
}

\section{Biography}

NARAYANAN KOMERATH

Professor and director of the John J. Harper wind tunnel, he leads the Georgia Tech Experimental Aerodynamics Group (EAG). He is a principal researcher in the Rotorcraft Center of Excellence since its inception in 1982, an Associate Fellow of AIAA and Fellow of the NASA Institute of Advanced Concepts. EAG projects have included the nearly 100 undergraduates since 1985 and include the Aerospace Digital Library: http://www.adl.gatech.edu

\section{MARILYN J. SMITH}

Associate Professor Marilyn J. Smith earned her Ph.D. in AE at Georgia Tech in 1994, and joined the AE faculty in 1997 after fifteen years of experience at Lockheed-Georgia, McDonnell-Douglas Helicopters and the Georgia Tech Research Institute. She was honored as the 1999 Outstanding Faculty Member by the GIT Women's Leadership Conference. She is an Associate Fellow of AIAA and has served on the AHS Fluids Technical Committee. 